\title{
Exercise training reduces high mobility group box-1 protein levels in women with breast cancer: findings from the DIANA-5 study
}

\author{
II training fisico riduce i livelli di high mobility group \\ box-1 protein in donne con cancro alla mammella: \\ risultati dallo studio DIANA-5
}

\begin{abstract}
Francesco Giallauria1, Marco Gentile², Paolo Chiodini3, Franco Berrino4, Amalia Mattiello2, Luigi Maresca1, Alessandra Vitelli1, Maria Mancini1, Alessandra Grieco1, Angelo Russo1, Rosa Lucci1, Giorgio Torella1, Salvatore Panico2, Carlo Vigorito1
\end{abstract}

\begin{abstract}
Exercise training reduces high mobility group box-1 protein levels in women with breast cancer: findings from the DIANA-5 study. F. Giallauria, M. Gentile, P. Chiodini, F. Berrino, A. Mattiello, L. Maresca, A. Vitelli, M. Mancini, A. Grieco, A. Russo, R. Lucci, G. Torella, S. Panico, C. Vigorito.

Purpose: To determine whether exercise training might exert anti-inflammatory effect by reducing HMGB1 levels in women with breast cancer (BC).

Methods: We analyzed monocentric data from the DIANA (DIET AND ANDROGENS)-5 PROJECT. Study population consisted of 94 patients randomized into two groups: 61 patients $(53 \pm 8 \mathrm{yrs}$, training group) were assigned to a structured exercise training intervention (3 times/week for the first 3 months, and once/week for the following 9 months); whereas 33 patients $(52 \pm 7$ yrs, control group) followed only the general indications to adhere to the life-style intervention suggestions of the DIANA protocol. At study entry and after 12 months, all patients underwent cardiopulmonary exercise testing, biochemical assessment [HMGB1, high-sensitivity C-reactive protein (hsCRP), interleukin-6 (IL-6)]; and lipid and glycemic profile.
\end{abstract}

Results: There were no significant differences between groups in baseline clinical and inflammatory profile. Among the training group, only 19/61 patients had high adherence to the exercise intervention. After stratifying the study population according to the level of adhesion to the exercise intervention, 1-year HMGB1 levels were lower among patients more adherent to exercise ( $p$ for trend=0.001). Further adjusting for age, body mass index and baseline values, 1-year HMGB1 levels remained significantly and inversely associated to the level of adhesion to the exercise intervention $(\mathrm{B}=-\mathbf{0 . 9 7}, \mathrm{SE}=\mathbf{0 . 4 3}, \mathrm{p}=\mathbf{0 . 0 1})$.

Conclusions: Moderate intensity exercise training in BC survivors is associated with reduced HMGB1 levels that are proportional to the level of adhesion to the exercise intervention, independently from other classical inflammatory molecules, suggesting an exercise-induced anti-inflammatory effect mediated by HMGB1.

Keywords: cancer, breast cancer, high mobility group box 1 protein, exercise training, cardiopulmonary exercise testing.

Monaldi Arch Chest Dis 2014; 82: 61-67.

${ }_{1}$ Department of Translational Medical Sciences. Division of Internal Medicine and Cardiac Rehabilitation, Federico II University, Naples, Italy.

2 Dipartimento di Medicina Clinica e Chirurgia, Federico II University, Naples, Italy.

3 Medical Statistics Unit, Second University of Naples, Naples, Italy.

4 Department of Preventive and Predictive Medicine, National Cancer Institute, Milan, Italy.

Corresponding Author: Francesco Giallauria, MD, PhD; Department of Translational Medical Sciences; Division of Internal Medicine and Cardiac Rehabilitation, Federico II University of Naples; Via S. Pansini 5; I-80131 Naples (NA), Italy; TellFax: +390817462639; E-mail address: giallauriafrancesco@gmail.com

\section{Introduction}

Breast cancer $(\mathrm{BC})$ is the most common cancer in women worldwide. It is also the principle cause of death from cancer among women globally. Studies on lifestyle and occurrence of $\mathrm{BC}$ indicate a key role for diet and physical activity; evidence is available on the potential influence of dietary modification on $\mathrm{BC}$ risk [1]. Data from the large European Investigation into Cancer and Nutrition (EPIC Study), which include Italian sub-cohorts are consistent with these main findings [2-7]; moreover the observational analysis on $\mathrm{BC}$ risk from the World Cancer Research Fund/American Institute for Cancer Research (WCRF/AICR) suggested that dietary recommendations was associated with reduced $\mathrm{BC}$ incidence in those individuals mostly adherent to the recommendations [8].

Epidemiological studies have also investigated and quite consistently reported a possible effect of physical activity on the incidence of primary $\mathrm{BC}$ [10-14]. In secondary prevention after BC diagnosis, observational studies consistently showed that the level of physical activity of $\mathrm{BC}$ women was cor- 
related to an improvement in several cancer-related outcomes. Several studies including physical intervention have also suggested that a formal program of exercise training is also able to improve several cancer-related outcomes in BC survivors [15-18].

Inflammation plays a crucial role in the development and evolution of cancer. Among several markers of inflammation, the high-mobility group box 1 protein (HMGB1) is emerging as a potential important mediator. HMGB1 is a highly conserved nuclear protein, acting as a chromatin-binding factor that binds DNA and promotes access to transcriptional protein assemblies on specific DNA targets $[19,20]$. Besides its nuclear role, HMGB1 also functions as an extracellular signaling molecule during inflammation, cell differentiation, cell migration, and tumor metastasis [19-22]. HMGB1 has been implicated in disease states, including sepsis [23], ischemia-reperfusion [24, 25], arthritis [26], meningitis [27], neurodegeneration [28], aging [29], and cancer $[30,31]$. In cancer, overexpression of HMGB1 is associated with each of the hallmarks of cancer [32]. Increased HMGB1 protein expression is found in primary human breast carcinomas compared with normal tissues, with HMGB1 mRNA present during mouse mammary development and with low amounts measured during periods of apoptotic activity [33].

To the best of our knowledge, the serum levels of HMGB1 and their changes after exercise interventions in women with $\mathrm{BC}$ have never been reported. Therefore, this study tested the hypothesis that exercise training might exert anti-inflammatory effect by reducing HMGB1 levels in BC women belonging to the DIANA-5 cohort.

\section{Methods}

\section{Study population}

The DIANA (Diet and Androgens)-5 study is a multicentre randomized controlled trial of the effectiveness of a diet based on Mediterranean and macrobiotic recipes and principles, associated with moderate physical activity, in reducing additional breast cancer (BC) events in women with early stage invasive $\mathrm{BC}$ at high risk of recurrence because of metabolic or endocrine milieu [34]. The overall design of the study has been described elsewhere [34]. We analyzed monocentric data (University of Naples "Federico II") consisting of 94 patients randomized into two groups: 61 patients (53 \pm 8 yrs, training group) were assigned to a structured exercise training intervention ( 3 times/week for the first 3 months, and once /week for the following 9 months); whereas 33 patients ( $52 \pm 7$ yrs, control group) received only general recommendations to adhere to the life-style intervention suggestions of the DIANA protocol. The study was conducted according to the guidelines of the Declaration of Helsinki, and our institutional ethical committee approved the protocol. The purpose of the protocol was explained to the patients and written informed consent was obtained from each patient before inclusion.

\section{Study protocol}

At the study enrollment and after 12 months, all patients underwent anthropometrical and biochem- ical assessment, cardiovascular clinical examination, and cardiopulmonary exercise stress testing. Before randomization, all women received a leaflet illustrating the WCRF/AICR recommendations for cancer prevention [35]. Training group patients were administered both the dietary and exercise training program as detailed below. After randomization, only the intervention group (training group, $61 \mathrm{pa}$ tients) underwent, in addition to exercise training sessions, a counseling dietary program supported by cooking classes, reinforcing meetings and print materials. The counseling program aimed at increasing leisure-time physical activity level, controlling weight, and promoting a healthy and low calorie diet. Control group (33 patients) received only general recommendations on life-style.

\section{Anthropometrical and biochemical assessment}

Body mass index (BMI) was used as a general measure of obesity and was calculated at the final visit as weight (kilograms) divided by height (meters squared). Waist circumference (WC), an index of abdominal obesity, was measured midway between the bottom of the rib cage and the top of the iliac crest. Blood pressure was measured twice after 5 min rest using a mercury sphygmomanometer. Anthropometric measurements were made with the subjects in indoor clothing and without shoes. Blood specimens were collected after 12- to 14-h fast, from 08:00 to 09:30 hours, to reduce the influence of circadian variation. Total cholesterol, triglyceride and high-density lipoprotein (HDL) cholesterol levels were measured using standard enzymatic methods [36]. Low-density lipoprotein (LDL) cholesterol was calculated according to the Friedewald formula. Fasting glucose levels were enzymatically determined by the peroxidase method. Fasting insulin levels were determined by enzyme immunoassay (Ultrasensitive Insulin Elisa, Mercodia, Sweden). Apolipoprotein B and high sensitivity C-reactive protein (hs-CRP) were measured with turbidimetric assay, using automated methods (Pentra 400 ABX Horiba, Italy). The error of the method was evaluated daily by analyzing a plasma pool and was $<5 \%$. The homeostatic assessment model (HOMA) index was used to estimate insulin resistance and calculated as fasting serum insulin (mU/L) $\mathrm{x}$ fasting serum glucose $(\mathrm{mM}) / 22.5$, as previously described [37]. Fasting HMGB1 levels were determined by enzyme immunoassay (HMGB1 Elisa, IBL International, Germany). Fasting high sensitivity IL-6 levels were determined by enzyme immunoassay (IL-6 Elisa, Diaclone, France). The inter-assay as well as the intra-assay coefficient was $<10 \%$.

\section{Cardiopulmonary exercise training testing}

Respiratory gas exchange measurements were obtained breath by breath with the use of a computerized metabolic cart (Vmax 29C, Sensormedics, Yorba Linda, CA, USA) as detailed elsewhere [24]. Briefly, after a 1-min warm-up period at 0 Watts workload, a ramp protocol of $20 \mathrm{~W} / \mathrm{min}$ was started and continued until exhaustion. The pedaling was kept constant at 55-65 revolutions/min. A 12-lead electrocardiogram (ECG) was monitored continuously during the test, and cuff blood pressure was 
manually recorded every 2 min. $\mathrm{VO}_{2 \text { peak }}$ was recorded as the mean value of $\mathrm{VO}_{2}$ during the last 20 s of the test and was expressed in milliliters per kilogram per minute. Predicted $\mathrm{VO}_{2 \text { peak }}$ was determined by use of a sex-, age-, height- and weight-adjusted and protocol-specific formula as previously detailed [24]. The ventilatory anaerobic threshold (VAT) was detected by use of the V-slope method. The VE versus $\mathrm{VCO}_{2}$ relationship was measured by plotting ventilation (VE) against carbon dioxide production $\left(\mathrm{VCO}_{2}\right)$ obtained every $10 \mathrm{~s}$ of exercise ( $\mathrm{VE} / \mathrm{VCO}_{2}$ slope): both $\mathrm{VE}$ and $\mathrm{VCO}_{2}$ were measured in liters per minute. The $\mathrm{VE} / \mathrm{VCO}_{2}$ slope was calculated as a linear regression function, excluding the non-linear part of the relationship after the onset of acidotic drive to ventilation [24].

\section{Exercise training program and cooking session}

Training group patients were enrolled in an inhospital structured exercise training program. The frequency goals of in-hospital exercise training sessions was 3 times/week for the first 3 months, and once /week for the following 9 months. Each session consisted of cycle or treadmill 30 min exercise, preceded by 5 min of warming and followed by 5 min of cooling down, at a work load of $75 \%$ of baseline peak $\mathrm{VO}_{2}$. This structured exercise training was on top of the general leisure-time physical activity recommendations or prescription of the general DIANA study (questionnaires, caloric control, etc, see above). From the 4th month to the 12th month, in-hospital exercise training sessions were reduced to one session/week, integrated with general leisure-time physical activity sessions, according to recommendations and prescription of the general DIANA study [34]. Training group was subdivided into 3 subgroups according to the adhesion to the in-hospital exercise training sessions: no sessions (group 1); 1 to 45 sessions per year (group 2); 46 to 130 sessions per year (group 3). During cooking sessions, patients were invited cooking and eating some dishes prepared according to the WCRF/AICR recommendations and inspired by a macrobiotic Mediterranean diet [35].

\section{Statistical Methods}

Continuous variables were reported as either mean and standard deviation (SD) or median and range according to their distribution, as assessed by the Shapiro-Wilk test. Categorical variables were reported as percentage. Differences in characteristics of patients among groups were tested by means of one-way ANOVA and Pearson chi-square test for continuous and categorical variables, respectively. A modified version of regression analysis, called TOBIT model was used to analyze HMGB1 values, where the normality assumption was not met because of the left-truncation for subjects with zero values [38]. Linear regression model and TOBIT (for HMGB1 values) were used to analyze one-year values including in the model physical category, age, BMI and baseline value. Trend test was also calculated where appropriate. Data were analyzed using SAS version 9.2 (SAS Inc, Cary, NC). All statistical tests were two-sided and p-values $<0.05$ were considered significant.

\section{Results}

Baseline characteristics of the study population are shown in Table 1. There were no significant differences between groups in baseline anthropometrical, BC characteristics, metabolic and inflammatory profile (Table 1).

The study period was similar in both groups. In training group, the average exercise intensity was $74.4 \pm 2.3 \%$ of baseline $\mathrm{VO}_{2 \text { peak }}$. No adverse events took place during any of training sessions in $\mathrm{BC}$ patients undergoing exercise training sessions.

Among the training group, 24 patients had very low adherence to the exercise intervention sessions, whereas 19 patients had high adherence. After stratifying the study population according to the level of adhesion to the exercise intervention sessions, 1year HMGB1 levels were lower among patients more adherent ( $\mathrm{p}$ for trend $=0.001$ ) (Table 2). After adjusting for age, body mass index and baseline values, 1-year HMGB1 levels were significantly and inversely associated to the level of adhesion to the exercise intervention $(\mathrm{B}=-0.97, \mathrm{SE}=0.43, \mathrm{p}=0.01)$ (Table 3). No significant correlations between exercise intervention and the other inflammatory mediators (hs-CRP and IL-6) were found (Table 3).

\section{Discussion}

To the best of our knowledge, this is the first study demonstrating an exercise training-induced reduction of HMGB1 levels in BC women. Notably, the reduction of HMGB1 levels is strongly correlated to the level of adhesion to exercise program and is more sensitive than that of other systemic inflammatory mediators such as hs-CRP and IL-6.

In cancer, overexpression of HMGB1 is associated with each of the hallmarks of cancer including unlimited replicative potential, angiogenesis, reduction of apoptosis, self-sufficiency in growth signals, and insensitivity to inhibitors of growth, inflammation, tissue invasion and metastasis [30]. In primary human breast carcinomas, increased HMGB1 protein expression has been found compared with normal tissues, with HMGB1 mRNA present during mouse mammary development with low amounts measured during periods of apoptotic activity [33].

The role of the immune system during cancer development is complex, involving extensive reciprocal interactions between genetically altered cells, adaptive and innate immune cells, their soluble mediators and structural components present within the tumor microenvironment. Immune system strictly regulates each stage of cancer development in most adult tumors. Whereas full activation of adaptive immune cells at the overt invasive tumor stage may result in eradication of malignant cells, chronic activation of innate immune cells at sites of premalignant growth may actually enhance tumor development. In addition, the balance between desirable antitumor immune responses and undesirable pro-tumor chronic inflammatory responses largely depends on the context in which a malignancy is developing [39]. HMGB 1 alerts the innate immune system to stress and excessive or unregulated cell death [40, 41]. 
Table 1. - Anthropometrical and clinical characteristics of the study population

\begin{tabular}{|c|c|c|c|}
\hline & Training Group $(n=61)$ & Control Group $(n=33)$ & $P$ value \\
\hline \multicolumn{4}{|l|}{ Anthropometrics } \\
\hline Age (yrs) & $53.5 \pm 8.6$ & $52.3 \pm 7.0$ & 0.505 \\
\hline Height $(\mathrm{cm})$ & $160.0 \pm 5.4$ & $158.9 \pm 4.9$ & 0.313 \\
\hline Weight $(\mathrm{Kg})$ & $71.6 \pm 14.1$ & $67.1 \pm 12.1$ & 0.120 \\
\hline Waist Circumference $(\mathrm{cm})$ & $96.0 \pm 14.9$ & $90.3 \pm 12.3$ & 0.065 \\
\hline Body Mass Index $\left(\mathrm{Kg} / \mathrm{m}^{2}\right)$ & $28.01 \pm 5.52$ & $26.57 \pm 4.60$ & 0.203 \\
\hline \multicolumn{4}{|l|}{ Breast Cancer Characteristics } \\
\hline Presence of invasive carcinoma (\%) & $61 / 61(100)$ & $33 / 33(100)$ & - \\
\hline Node positivity (\%) & $49(n=30 / 61)$ & $55(n=18 / 33)$ & 0.624 \\
\hline Estrogen positivity (\%) & $84(n=51 / 61)$ & $82(n=27 / 33)$ & 0.828 \\
\hline \multicolumn{4}{|l|}{ Metabolic and Hormonal Profile } \\
\hline Glycemia (mg/dL) & $93.5 \pm 12.5$ & $92.2 \pm 15.5$ & 0.669 \\
\hline Insulin $(\mathrm{ng} / \mathrm{mL})$ & $7.76 \pm 4.03$ & $8.80 \pm 5.00$ & 0.278 \\
\hline HOMA index & $1.836 \pm 1.192$ & $2.042 \pm 1.250$ & 0.435 \\
\hline Total Cholesterol (mg/dL) & $202.3 \pm 35.7$ & $203.4 \pm 32.0$ & 0.885 \\
\hline LDL-Cholesterol (mg/dL) & $128.1 \pm 35.1$ & $120.1 \pm 29.4$ & 0.264 \\
\hline HDL-Cholesterol (mg/dL) & $54.6 \pm 11.59$ & $55.8 \pm 13.7$ & 0.659 \\
\hline Triglycerides (mg/dL) & $100.6 \pm 46.9$ & $119.6 \pm 72.0$ & 0.126 \\
\hline Testosterone $(\mathrm{nmol} / \mathrm{L})$ & $0.361 \pm 0.362$ & $0.383 \pm 0.259$ & 0.756 \\
\hline \multicolumn{4}{|l|}{ Inflammatory Markers } \\
\hline hsCRP (mg/dL) [n=82] & $1.3 \pm 1.7$ & $0.9 \pm 1.1$ & 0.492 \\
\hline IL-6 (pg/mL) [n=82] & $1.3 \pm 1.3$ & $1.4 \pm 1.4$ & 0.254 \\
\hline HMGB1 (ng/mL) & $0.9 \pm 1.4$ & $1.3 \pm 1.5$ & 0.337 \\
\hline
\end{tabular}

Captions: HOMA, homeostatic assessment model; LDL, low-density lipoprotein; HDL, high-density lipoprotein; hsCRP, high sensitivity C-reactive protein; IL-6, interleukin-6; HMGB1, high mobility group box-1.

Table 2. - One-year metabolic and inflammatory parameters according to the level of adhesion to the exercise intervention (3=highest)

\begin{tabular}{|c|c|c|c|c|c|c|}
\hline \multirow{3}{*}{ Phisical Category } & \multirow{2}{*}{$\mathbf{0}$} & \multirow{2}{*}{1} & \multirow{2}{*}{2} & \multirow{2}{*}{3} & $P$ value & $P$ value \\
\hline & & & & & \multicolumn{2}{|c|}{ (between groups) } \\
\hline & $(\mathrm{N}=33)$ & $(\mathrm{N}=24)$ & $(\mathrm{N}=18)$ & $(\mathrm{N}=19)$ & & trend test \\
\hline Triglycerides (mg/dL) & $104.00 \pm 44.03$ & $105.83 \pm 41.00$ & $93.61 \pm 31.11$ & $80.16 \pm 33.02$ & 0.122 & 0.029 \\
\hline Total Cholesterol (mg/dL) & $205.09 \pm 36.64$ & $193.67 \pm 36.85$ & $202.00 \pm 28.79$ & $194.84 \pm 39.03$ & 0.607 & 0.423 \\
\hline HDL Cholesterol (mg/dL) & $56.61 \pm 16.21$ & $51.04 \pm 16.28$ & $53.89 \pm 12.94$ & $58.37 \pm 11.87$ & 0.373 & 0.741 \\
\hline LDL Cholesterol (mg/dL) & $127.67 \pm 34.92$ & $119.88 \pm 38.25$ & $129.44 \pm 30.59$ & $120.37 \pm 32.39$ & 0.719 & 0.648 \\
\hline BMI $\left(\mathrm{Kg} / \mathbf{m}^{2}\right)$ & $26.31 \pm 4.41$ & $29.67 \pm 7.08$ & $27.25 \pm 3.83$ & $25.41 \pm 4.07$ & 0.034 & 0.526 \\
\hline HMGB-1 (ng/mL)* & $\begin{array}{c}0.50 \\
{[0.00-3.60]}\end{array}$ & $\begin{array}{c}1.15 \\
{[0.00-4.10]} \\
\end{array}$ & $\begin{array}{c}0.00 \S \\
{[0.00-3.10]}\end{array}$ & $\begin{array}{c}0.00 \S \\
{[0.00-0.60]}\end{array}$ & 0.001 & 0.001 \\
\hline hsCRP (mg/dL) & $0.78 \pm 1.12$ & $1.63 \pm 1.76$ & $1.67 \pm 1.89$ & $0.99 \pm 1.05$ & 0.145 & 0.668 \\
\hline IL-6 (pg/mL) & $1.66 \pm 1.68$ & $1.53 \pm 0.81$ & $1.78 \pm 2.34$ & $0.95 \pm 0.66$ & 0.328 & 0.209 \\
\hline
\end{tabular}

Values are mean and standard deviation; * values were median and range, p-value from Tobit model.; $\S 0=$ not detectable

Captions: LDL, low-density lipoprotein; HDL, high-density lipoprotein; hsCRP, high sensitivity C-reactive protein; IL-6, interleukin-6; HMGB1, high mobility group box-1. 


\begin{tabular}{|c|c|c|c|c|c|c|c|c|c|}
\hline \multirow{2}{*}{ Phisical Category } & \multirow{2}{*}{$\begin{array}{c}\mathbf{0} \\
\text { (Reference) }\end{array}$} & \multicolumn{2}{|c|}{1} & \multicolumn{2}{|c|}{2} & \multicolumn{2}{|c|}{3} & \multirow[t]{2}{*}{$P$ value } & \multirow{2}{*}{$\frac{P \text { value }}{\text { (trend test) }}$} \\
\hline & & $\beta$ & SE & $\beta$ & SE & $\beta$ & SE & & \\
\hline Hs-CRP (mg/dL) & 0 & 0.59 & 0.36 & 0.53 & 0.38 & 0.13 & 0.37 & 0.306 & 0.755 \\
\hline IL-6 (pg/mL) & 0 & -0.34 & 0.47 & 0.11 & 0.49 & -0.68 & 0.48 & 0.594 & 0.289 \\
\hline HMGB-1 (ng/mL)* & 0 & 0.42 & 0.37 & -0.71 & 0.42 & -0.97 & 0.43 & 0.008 & 0.010 \\
\hline
\end{tabular}

*estimated from Tobit model.

Captions: hsCRP, high sensitivity C-reactive protein; IL-6, interleukin-6; HMGB1, high mobility group box-1.

HMGB1 mediates a number of important functions including stimulating the release of tumor necrosis factor (TNF)- $\alpha$, interleukin (IL)-1 $\beta$, and other inflammatory products, endothelial cell activation, recruitment and activation of innate immune cells, and also dendritic cell maturation that, in the setting of cancer, lead to a chronic inflammatory response [21].

Epidemiological studies have shown that the level of physical exercise is associated to improved outcome in BC patients, included cancer related and total mortality [11-14]. Moderate intensity exercise interventions in postmenopausal breast cancer (i.e. $\left.60 \% \mathrm{VO}_{2 \text { peak }}\right)$ are associated with several favorable effects in several cancer-related outcomes, such as physical and psychological function and quality of life $[42,43]$. Several factors mediate the relationship between exercise, inflammation and immune system. The individual characteristics, type and intensity of exercise, as well as the timing of cancer diagnosis and stage may have an interplay role. Both the incidence of cancer, chronic inflammatory status and the impairment of the immune system also show negative age-related changes that can partially be counteracted with exercise [44]. Weight loss, reduced levels of insulin, glucose, and sex hormones, decreased inflammation and immunostimulation might also explain the beneficial effects of exercise on cancer outcomes [15-18, 45, 46]. However, these effects mainly depend on type and duration of exercise; and the clinically relevant cut-off points of the exercise-induced anti-inflammatory response are still largely unknown within the context of cancer. In fact, it should be noted that reduced inflammatory status, enhanced immune function and low susceptibility to cancer occur with regular moderate exercise, whereas sedentary habits and exhaustive exercise suppress immune system inducing a pro-inflammatory state and higher oxidative DNA damage, both of which are hypothesized to be markers of cancer recurrence [47]. The present study showed that the reduction of HMGB1 is proportional to the level of adherence to 1 -year exercise intervention of moderate intensity; whereas no effect was found on other classical inflammatory molecules such as hs-CRP or IL-6. It could be hypothesized that exercise training may exert an early anti-inflammatory effect mediated by HMGB1 at nuclear level. Whether exercise-induced reduction of HMGB1 might have prognostic impact on BC survivors should be investigated.

\section{Study limitations}

A number of limitations of the present study should be considered. Training patients underwent moderate intensity exercise program: whether an exercise program of higher intensity might have additional clinical and prognostic value should be clarified. Moreover, exercise training attendance was good in 19 out of 61 patients, highlighting the gender specific difficulties in attending long-term exercise training programs as previously described in women with cardiovascular disease attending cardiac rehabilitation programs [48]. Despite the aforementioned limitations, this study has several unique strengths. This is the first study enrolling high-risk BC survivors (women with early stage invasive $\mathrm{BC}$ at high risk of recurrence because of metabolic or endocrine milieu) to 1 -year exercise intervention, and the first to demonstrate a reduction of a potent inflammatory marker such as the HMGB1 protein in these high risk patients.

\section{Conclusions}

Moderate intensity exercise training in BC survivors is associated with reduced HMGB1 levels that are proportional to the level of adhesion to the exercise program. The correlation to exercise dose is more sensitive than that observed for other systemic inflammatory mediators such as hs-CRP and IL-6. These results confirm that exercise training-n favorably modulate the inflammatory status in high risk $\mathrm{BC}$ patients. Further studies are needed in order to evaluate whether the reduction of HMGB1 levels has prognostic value in $\mathrm{BC}$ women.

\section{Riassunto}

Scopi: Determinare se un programma di training fisico esplica un potere antinfiammatorio riducendo i livelli di HMGBl in donne con cancro alla mammella $(C M)$.

Metodi: Sono stati analizzati dati monocentrici del progetto DIANA (DIET AND ANDROGENS)-5. La popolazione di studio consiste di 94 pazienti ran-

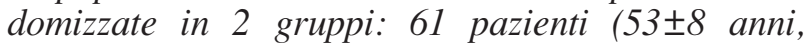
gruppo training) sono state assegnate ad un programma strutturato di training fisico (3 volte alla settimana per i primi 3 mesi, poi 1 volta alla settimana 
per successive 9 mesi); mentre 33 pazienti $(52 \pm 7$ anni, gruppo controllo) hanno seguito soltanto indicazioni generiche ad aderire a corretto stile divita in accordo al protocollo DIANA. All'arruolamento $e$ dopo 12 mesi, tutte le pazienti hanno effettuato test cardiopolmonare, valutazione biochimica (HMGB1, proteina $C$-reattiva ad alta sensibilitá ( $h s P C R)$, interleuchina 6 (IL-6); profilo lipidico e glicemico.

Risultati: Non sono state osservate differenze tra i gruppi circa il profilo clinico e infiammatorio a livello basale. Tra le donne appartenenti al gruppo training, soltanto 19/61 pazienti mostravano una alta aderenza al programma di esercizio. Dopo stratificazione per il livello di adesione al programma di esercizio, i livelli di HMGB1 ad 1 anno erano significativamente inferiori nei pazienti con una maggiore adesione al programma di esercizio ( $p$ per trend=0.001). L'analisi multivariate ha mostrato che dopo aggiustamento per etá, indice di massa corporea e valori basali di HMGB1, $i$ valori di HMGB1 ad 1 anno restavano significativamente ed inversamente associati al livello di adesione al programma di esercizio $(B=-0.97, S E=0.43, p=0.01)$.

Conclusioni: Un programma di training di intensitá moderata in donne con CM è associato a ridotti livelli di HMGB1, in maniera proporzionale al livello di adesione al programma di esercizio, indipendentemente dai classici parametri infiammatori, suggerendo un effetto antinfiammatorio indotto dall' esercizio mediato dall' HMGB1.

Parole chiave: cancro; cancro alla mammella; high mobility group box 1 protein; esercizio fisico; test da sforzo cardiopolmonare.

Aknowledgment: The DIANA-5 Project was financed by the Italian Association for Cancer Research (AIRC, Grant $n^{\circ} 11942$ ) and by the Italian Department of Health (PIO program). This study was also financed by the FARO (Fondo per l'Avvio di Ricerche Originali).

\section{References}

1. http://www.ncbi.nlm.nih.gov/pubmed/?term=diet+and+ breast+cancer+and+meta-analysis. Accessed January 20, 2014

2. Ferrari P, Rinaldi S, Jenab M, et al. Dietary fiber intake and risk of hormonal receptor-defined breast cancer in the European Prospective Investigation into Cancer and $\mathrm{Nu}-$ trition study. Am J Clin Nutr 2013; 97: 344-53.

3. Romieu I, Ferrari P, Rinaldi S, et al. Dietary glycemic index and glycemic load and breast cancer risk in the European Prospective Investigation into Cancer and Nutrition (EPIC). Am J Clin Nutr 2012; 96: 345-55.

4. Buckland G, Travier N, Cottet V, et al. Adherence to the mediterranean diet and risk of breast cancer in the European prospective investigation into cancer and nutrition cohort study. Int J Cancer 2013; 132: 2918-27.

5. Sieri S, Krogh V, Ferrari P, et al. Dietary fat and breast cancer risk in the European Prospective Investigation into Cancer and Nutrition. Am J Clin Nutr 2008; 88: 1304-12.

6. Tjønneland A, Christensen J, Olsen A, et al. Alcohol intake and breast cancer risk: the European Prospective Investigation into Cancer and Nutrition (EPIC). Cancer Causes Control 2007; 18: 361-73.

7. Schütze M, Boeing H, Pischon T, et al. Alcohol attributable burden of incidence of cancer in eight European countries based on results from prospective cohort study. BMJ 2011; 342: d1584.
8. Romaguera D, Vergnaud AC, Peeters PH, et al. Is concordance with World Cancer Research Fund/American Institute for Cancer Research guidelines for cancer prevention related to subsequent risk of cancer? Results from the EPIC study. Am J Clin Nutr 2012; 96: 150-63.

9. http://www.ncbi.nlm.nih.gov/pubmed/?term=physical+ activity+and+breast+cancer+and+meta-analysis. Accessed January 20, 2014

10. Ibrahim EM, Al Homaidh A. Physical activity and survival after breast cancer diagnosis: meta-analysis of published studies. Med Oncol 2011; 28: 753-65.

11. Holick CN, Newcomb PA, Trentham-Dietz A, et al. Physical activity and survival after diagnosis of invasive breast cancer. Cancer Epidemiol Biomarkers Prev 2008; 17: 379-86.

12. Holmes MD, Chen WY, Feskanich D, Kroenke CH, Colditz GA. Physical activity and survival after breast cancer diagnosis. JAMA 2005; 293: 2479-486.

13. Sternfeld B, Weltzien E, Quesenberry CP Jr, et al. Physical activity and risk of recurrence and mortality in breast cancer survivors: findings from the LACE study. Cancer Epidemiol Biomarkers Prev 2009; 18: 87-95.

14. Ballard-Barbash R, Friedenreich CM, Courneya KS, Siddiqi SM, McTiernan A, Alfano CM. Physical activity, biomarkers, and disease outcomes in cancer survivors: a systematic review. J Natl Cancer Inst 2012; 104: 815-40.

15. McTiernan A. Mechanisms linking physical activity with cancer. Nat Rev Cancer 2008; 8: 205-11.

16. Spence RR, Heesch KC and Brown WJ. Exercise and cancer rehabilitation: a systematic review. Cancer Treat Rev 2010; 36: 185-94.

17. Gleeson M, Bishop NC, Stensel DJ, Lindley MR, Mastana SS, Nimmo MA. The anti-inflammatory effects of exercise: mechanisms and implications for the prevention and treatment of disease. Nat Rev Immunol 2011; 11: 607-15.

18. Goh J, Kirk EA, Lee SX, Ladiges WC. Exercise, physical activity and breast cancer: the role of tumor-associated macrophages. Exerc Immunol Rev 2012; 18: 158-76.

19. Lotze MT, Tracey KJ. High-mobility group box 1 protein (HMGB1): nuclear weapon in the immune arsenal. Nat Rev Immunol 2005; 5: 331-42.

20. Müller S, Scaffidi P, Degryse B, et al. New EMBO members' review: the double life of HMGB1 chromatin protein: architectural factor and extracellular signal. EMBO J 2001; 20: 4337-40.

21. Dong Xda E, Ito N, Lotze MT, et al. High mobility group box I (HMGB1) release from tumor cells after treatment: implications for development of targeted chemoimmunotherapy. J Immunother 2007; 30: 596-606.

22. Ellerman JE, Brown CK, de Vera M, et al. Masquerader: high mobility group box-1 and cancer. Clin Cancer Res 2007; 13: 2836-48.

23. Wang H, Yang H, Tracey KJ. Extracellular role of HMGB1 in inflammation and sepsis. J Intern Med 2004; 255: 320-31.

24. Cirillo P, Giallauria F, et al. Increased high mobility group box-1 protein levels are associated with impaired cardiopulmonary and echocardiographic findings after acute myocardial infarction. J Card Fail 2009; 15: 362-7.

25. Cirillo P, Giallauria F, Di Palma V, et al. Cardiovascular disease and High-Mobility Group Box-1. Is a new inflammatory killer in town? Angiology 2013; 64:343-55.

26. Andersson U, Tracey KJ. HMGB1 as a mediator of necrosis-induced inflammation and a therapeutic target in arthritis. Rheum Dis Clin North Am 2004; 30: 627-637, xi.

27. Tang D, Kang R, Cao L, et al. A pilot study to detect high mobility group box 1 and heat shock protein 72 in cerebrospinal fluid of pediatric patients with meningitis. Crit Care Med 2008; 36: 291-5.

28. Qi ML, Tagawa K, Enokido Y, et al. Proteome analysis of soluble nuclear proteins reveals that HMGB1/2 suppress genotoxic stress in polyglutamine diseases. Nat Cell Biol 2007; 9: 402-14. 
29. Enokido $\mathrm{Y}$, Yoshitake A, Ito $\mathrm{H}$, et al. Age-dependent change of HMGB1 and DNA double-strand break accumulation in mouse brain. Biochem Biophys Res Commun. 2008; 376: 128-33.

30. Tang D, Kang R, Zeh HJ 3rd, Lotze MT. High-mobility group box 1 and cancer. Biochim Biophys Acta 2010; 1799: 131-40.

31. Mantovani A. Cancer: Inflaming metastasis. Nature 2009; 457: 36-7.

32. Brezniceanu ML, Völp K, Bösser S, et al. HMGB1 inhibits cell death in yeast and mammalian cells and is abundantly expressed in human breast carcinoma. FASEB $J$ 2003; 17: 1295-7.

33. Flohr AM, Rogalla P, Meiboom M, et al. Variation of HMGB1 expression in breast cancer. Anticancer Res 2001; 21: 3881-5.

34. Villarini A, Pasanisi P, Traina A, et al. Lifestyle and breast cancer recurrences: the DIANA-5 trial. Tumori 2012; 98: 1-18.

35. http://www.dietandcancerreport.org/cancer_prevention recommendations/index.php. Accessed January 20, 2014

36. Gentile M, Panico S, Mattiello A, et al. Association between small dense LDL and early atherosclerosis in a sample of menopausal women. Clin Chim Acta 2013; 426: $1-5$.

37. Matthews DR, Hosker JP, Rudenski AS, Naylor BA, Treacher DF, Turner RC. Homeostasis model assessment: insulin resistance and beta-cell function from fasting plasma glucose and insulin concentrations in man. Diabetologia 1985; 28: 412-9.

38. Tobin J. Estimation of relationships for limited dependent variables. Econometrica 1958. 26: 24-36.
39. de Visser KE, Coussens LM. The inflammatory tumor microenvironment and its impact on cancer development. Contrib Microbiol 2006; 13: 118-37.

40. Lotze MT, Zeh HJ, Rubartelli A, et al. The grateful dead: damage-associated molecular pattern molecules and reduction/oxidation regulate immunity. Immunol Rev 2007; 220: 60-81.

41. Zeh HJ 3rd, Lotze MT. Addicted to death: invasive cancer and the immune response to unscheduled cell death. J Immunother 2005; 28: 1-9.

42. Cramp F, Byron-Daniel J. Exercise for the management of cancer-related fatigue in adults. Cochrane Database Syst Rev 2012; 11:CD006145.

43. Mishra SI, Scherer RW, Snyder C, Geigle PM, Berlanstein DR, Topaloglu O. Exercise interventions on health-related quality of life for people with cancer during active treatment. Cochrane Database Syst Rev 2012; 8:CD008465.

44. Walsh NP, Gleeson M, Shephard RJ, et al. Position statement. Part one: Immune function and exercise. Exerc Immunol Rev 2011; 17: 6-63.

45. Ligibel JA, Giobbie-Hurder A, Olenczuk D, et al. Impact of a mixed strength and endurance exercise intervention on levels of adiponectin, high molecular weight adiponectin and leptin in breast cancer survivors. Cancer Causes Control 2009; 20: 1523-8.

46. Irwin ML, Mayne ST. Impact of nutrition and exercise on cancer survival. Cancer J 2008; 14: 435-41.

47. Rowbottom DG, Green KJ. Acute exercise effects on the immune system. Med Sci Sports Exerc 2000; 32: S396-405.

48. Daniels KM, Arena R, Lavie CJ, Forman DE. Cardiac rehabilitation for women across the lifespan. Am J Med. 2012; 125: 937.e 